\title{
The rise of policy coherence for development: a multi-causal approach
}

\begin{abstract}
In recent years policy coherence for development (PCD) has become a key principle in international development debates, and it is likely to become even more relevant in the discussions on the post-2015 sustainable development goals. This article addresses the rise of PCD on the Western donors' aid agenda. While the concept already appeared in the work of Organisation for Economic Co-operation and Development (OECD) in the early 1990s, it took until 2007 before PCD became one of the Organisation's key priorities. We adopt a complexity-sensitive perspective, involving a process-tracing analysis and a multi-causal explanatory framework. We argue that the rise of PCD is not as contingent as it looks. While actors such as the EU, the DAC and OECD Secretariat were the 'active causes' of the rise of PCD, it is equally important to look at the underlying 'constitutive causes' which enabled policy coherence to thrive well.

KEYWORDS: policy coherence for development, Organisation for Economic Co-operation and Development, Development Assistance Committee, multi-causality, Aristotle
\end{abstract}

\section{Introduction}

Arguably, one of the most prominent concepts in the discussions on the post-2015 framework is that of policy coherence for development (PCD) referring to the general idea that non-aid policies of donor countries have an impact on development countries and therefore should take into account the latter's needs and interests (Forster \& Stokke, 1999a). Indeed, the principle of PCD is seen by many as a part of the solution to establish a "truly international framework of policies to achieve sustainable development" (UN, 2013: 2) in the post-2015 era. However, and as already outlined in the introduction to this special issue, it remains unclear what the concept of PCD entails and how it could feature as a tool for transformative development.

The central aim of this study is to extend our understanding of the concept of PCD. More specifically, we seek to explain the rise of the concept on the Western donor's aid agenda. While donor countries 
traditionally had a lukewarm attitude towards its promotion (Forster \& Stokke, 1999b; Ashoff, 2005; Carbone 2009), since the mid-2000s the concept has become 'one of the most hotly debated issues among donors' (Hoebink 2010b: 9) and has increasingly been seen within policy circles as a tool for transformative development (DIIS, 2013; ECDPM, 2014; ODI, DIE, \& ECDPM, 2013; OECD, 2013b). This shift is most clearly reflected in the work of the Organisation for Economic Co-operation and Development (OECD) and its Development Assistance Committee (DAC). While the DAC already introduced the concept of PCD in 1991, only limited progress was made throughout the 1990s and early 2000s to develop and promote it. Moreover, the concept was framed negatively, in terms of avoiding policy incoherence (Carbone, 2009; Forster \& Stokke, 1999b). As we will show in this article, it took until 2007 before PCD became a central issue on the OECD's political agenda and was further elaborated as a tool for transformative development. It continues to figure prominently in the work of the OECD until today, as reflects from the OECD Strategy on Development (2012a) or the new DAC mandate (2011), which both put forward the concept as a key development principle. Moreover, several efforts have been undertaken to further advance it and place PCD at the heart of the post-2015 discussions (ECDPM, 2014; OECD, 2013b, 2014a, 2014b).

Importantly, literature has not addressed the rise of PCD on the Western donors' aid agenda. Indeed, while there is an emerging literature on how OECD donors promote PCD at the institutional level, both in general (e.g. Ashoff, 1999; 2005; Carbone, 2009; Forster \& Stokke, 1999b; Hoebink, 1999; Stroß, 2014) and within a particular policy field (e.g. Makhan, 2012; Morrissey, 1999; Youngs, 2007), scholars thus far paid little attention to why donors increasingly attach importance to the principle of PCD. Most notable exceptions are the studies of Chandler (2007) and Thede (2013), though, both focus on the securitydevelopment nexus. The central aim of this article is to address the 'why' behind the rise of PCD in all its aspects.

Some tentative explanations for the rise of PCD on the Western donor's aid agenda have been suggested. The European Union (EU), for example, has been undertaking a series of efforts from 2005 onwards to promote PCD vis-à-vis its Member States and the development community at large (Carbone, 2008; Hoebink, 2010; Stroß, 2014) and the EU has been called "one of the leading proponents of PCD in the OECD/DAC" (ODI et al., 2013: 22). It could also be that the concept of PCD thrives well in today's globalized world in which the boundaries between different policy areas and levels have become blurred, forcing donors to think 'beyond aid' (Klingebiel, \& Paulo, 2014). It is also possible that donor countries have taken the criticism on their incoherent policies to the heart and aim to increase the 
impact of their aid (OECD/DAC, 2005, 2008f), or perhaps the promotion of PCD is not good at all, serving the interests of Western donors (Chandler, 2007). It may also reflect a commitment to neoliberalism (Thede, 2013). Another option is that the rise of PCD can be attributed to the efforts of the OECD and DAC Secretariat, or more specifically to OECD Secretary-General Angel Gurría who has taken a particular interest in the topic (Manning, 2008). In sum, various (f)actors may have contributed to the rise of PCD on the Western donors' aid agendas. However, given the absence of systematic and comprehensive studies on this topic ${ }^{1}$, it is impossible to tell if and how these relate to one another, let alone whether they have explanatory power or need to be complemented with alternative explanations. Therefore, the central aim of this study is to unravel the underlying puzzle of ' $w h y^{\prime}$ PCD thrives well in recent years.

We do so by adopting a complexity-sensitive perspective, which has ontological, epistemological and methodological implications (see Figure 1). Ontologically, and in line with critical realist assumptions, we recognize that social reality consists of multiple strata in which different causal mechanisms interact in a complex manner (Bailey, 2008). This allows us to provide a more 'stratified and integrated, and therefore more adequate, account' (Bailey 2008: 232) of the (f)actors that enabled the rise of PCD on the Western aid agenda. Epistemologically, this requires a multi-causal approach to social reality (Eun, 2012; McKelvey, 2004). Hence, by embracing a deeper and broader meaning of 'cause' we accept that factors not inevitably 'push and pull' in a 'when A, then B manner' but rather 'constrain and enable' in complex combinations (Kurki 2006; Eun 2012). Applied to our case, it leads us to think beyond seemingly obvious causes such as the impact of the EU, the DAC secretariat, or specific individuals, by putting these into perspective and relating them to other sorts of causes.

One way to engage in a multi-causal analysis is to use an Aristotle framework on causality. Aristotle identified four types of causes - material, efficient, final and formal causes - each offering a different perspective on why a certain phenomenon took place. While traditional accounts usually take a narrow view in terms of efficient causes, this framework provides us a deeper understanding of the 'why' as it also elaborates on various types of causes and how they relate to one another. Moreover, it has several advantages compared to other approaches that combine different causal explanations, such as the often-made distinction between interests, ideas and institutions (e.g. Cox 1981; Hall, 1997; Williams, 2005). First, the Aristotelian causality does not distinguish between ideas and interests. For example, as elaborated more in the next sections, 'material' causes according to Aristotle contain both interest- and ideas-related components. While this might be confusing from a theoretical realist or Marxist point of view, it is helpful from the ontological position that ideas and interests cannot be disentangled. To give a 
specific example: it may be a futile exercise to try to determine whether and to what extent the pro-PCD stance of the Nordic countries or the DAC Secretariat stem from their ideological background or from self-interests; what matters more is to understand how this complicated amalgamation of preferences has contributed to (indeed 'caused') the rise of PCD. Second, when looking for causes, the Aristotelian framework allows us to transcend the traditional but increasingly sterile debate between positivist 'explaining' and post-positivist 'understanding' approaches. As Kurki (2008: 296-297) has convincingly argued "the active powers of agents (efficient causes) must always be related to final causes (purposes, intentionality) and, crucially, be contextualized within the "constitutive" conditioning causal powers of rules and norms (formal causes) as well as material conditions (material causes)". Third, the Aristotelian approach opens space for agency-centred and structure-oriented explanations and for the interaction between both. Again, this allows for a comprehensive and complexity-sensitive explanation. At the same time, however, its embeddedness within a critical realist ontology (e.g. Kurki 2008; Bailey, 2008) implies a multi-layered perspective on ever-deeper levels of explanation. Specifically, as will become clear below (see also Figure 1), at the end of the day 'formal causes' provide a deeper understanding than the other causes.

In brief, an Aristotelian approach to causality offers a fruitful approach to some of the grand debates in IR, namely on ideas-interests, explaining-understanding, and agency-structure. Some studies have advocated such an approach in IR (Kurki, 2008; McKelvey, 2004; Wendt, 2003). However, these calls have remained largely unanswered, notwithstanding some partial exceptions (e.g. Bailey, 2008; Jutila, 2009). An Aristotle framework on causality has proven its merits in others social sciences such as psychology, health or business (e.g. McKelvey, 2004; Pérez Álvarez, 2009; Sunday, Eyles, \& Upshur, 2001), but to our knowledge applications in the field of development studies are missing. For these reasons, the least one can say is that the Aristotle approach offers a potentially fruitful avenue for research. By providing one of the first empirical applications of the framework in IR and development studies, we aim to make an original contribution to the literature and lay the basis for further research.

Methodologically, we apply process-tracing to reconstruct how the concept of PCD made its way up the agenda of the OECD and DAC (Bennett \& George, 2005). The data for this study were obtained through semi-structured interviews with in total 28 OECD, DAC and Member States' officials ${ }^{2}$, archive study and document analysis (e.g. minutes of meetings, working reports, intra-delegations' correspondence) and participatory observation ${ }^{3}$. 
The remainder of this article is structured as follows. The next section provides a process-tracing analysis of how the concept of PCD made its way up the political agenda of the OECD and the DAC. Subsequently, section three discusses the different causes underlying the rise of PCD within the OECD system from 2007 onwards. The paper concludes with some general reflections on the main findings of this study, linking them to the broader question of this special issue "What role for PCD in the post-2015 framework".

\section{The rise of PCD within the OECD}

The principle of PCD came to the fore in the OECD ${ }^{4}$ in December 1991, when it was first discussed at the DAC's annual High-Level Meeting. In the light of the ending of the Cold War, which profoundly altered the North-South relations, the DAC called for greater coherence in the policies of its members vis-à-vis the developing world in order to make aid more effective (Carbone, 2008; Forster \& Stokke, 1999a). More specifically, the DAC Secretariat (hereafter Development Co-operation Directorate or DCD) put forward an agenda which revolved around four key priorities, namely (i) establishing a clear-cut definition of PCD, (ii) developing a methodology to assess the cost of policy incoherence, (iii) identify best practices in the promotion of PCD and (iv) promoting horizontal work within the OECD on PCD related issues. Moreover, the DAC called for PCD at various levels, respectively, within the framework of a country's development policies, within the framework of domestic and foreign policies (e.g. agriculture, trade, migration) and within the framework of donors' policies vis-à-vis the developing world (OECD/DAC, 1991, 1991b, 1991c, 1992).

However, while the DAC successfully drew international attention to the need of greater policy coherence, few further efforts were undertaken to implement this agenda (Carbone, 2008; Forster \& Stokke, 1999b). On the contrary, in the subsequent years the focus of its work lay on good governance, aid effectiveness and participatory development. Furthermore, the DAC reviewed in 1993 its list of ODAeligible countries and in 1995 it initiated a so-called 'exercise de réflection' to reevaluate the role of development cooperation in the $21^{\text {st }}$ century (Führer, 1996; OECD/DAC, 1994a; 1994b). This being said, the issue of PCD did not fall completely off the radar during the 1990s. At a rhetorical level, the principle was reaffirmed on several occasions, most notably in the DAC's report 'Shaping the $21^{\text {st }}$ century'. However, while this report put forward a series of well-defined international development goals, its provisions on PCD were short and ambiguous (OECD/DAC, 1996b). In a similar vein, the principle of policy coherence was also reaffirmed on other occasions, though, typically in the margins of discussions 
on other - more important - discussions such as the establishment of the MDGs or financing for development (Führer, 1996; OECD/DAC, 1994a,1995, 1996a).

Also at the beginning of the new Millennium, the promotion of PCD was not considered to be a priority. In 2000, for example, the DCD and a coalition of countries (i.e. Belgium, Canada, Netherlands and UK) were keen on placing the issue of PCD more central in the work of the $O E C D^{5}$, though, failed in doing so (OECD/DAC, 2000a; 2000b; interviews 8,14). In 2002, the same countries pushed the OECD's Ministerial Council to adopt the 'OECD action for a shared development agenda', which called upon the Organisation to 'enhance the understanding of the development dimension of member country policies and their impact on developing countries' (OECD, 2002). However, and similar to the early 1990s, few efforts were undertaken to implement this agenda. In fact, the only important achievement was the inclusion of a PCD chapter in the DAC's peer reviews from 2002 onwards (OECD/DAC, 2002). Consequently, DAC donors were forced - at least to some extent - to pay attention to policy coherence in their policies vis-à-vis the developing world. Moreover, it allowed the DCD to identify best practices on how to promote PCD at the institutional level (Manning, 2008; interview 14). Nonetheless, the inclusion of PCD in the DAC peer reviews was in many aspects also a missed opportunity. Indeed, since the DAC did not put forward a clear definition, nor measurement of the concept, it was impossible to systematically track progress on the issue (Carbone, 2009; Picciotto, 2005; interviews 2,4,10,21). Moreover, by focusing exclusively on how to achieve PCD at the institutional level (i.e. how to avoid policy incoherence), the DAC did not address the larger question of what potential positive synergies exist between development cooperation and other policy fields such as agriculture, health, trade or migration (interviews 5,14,21,22).

From 2007 onwards, the concept of PCD rapidly made its way up the political agenda of the OECD. More specifically, while the DAC had traditionally been the main (and often only) advocate of PCD -focusing on the institutional dimension of policy coherence, the OECD Secretariat-General increasingly took an interest in enhancing the understanding of PCD. More specifically, the OECD established in 2007 a socalled PCD-unit within the office of the Secretariat-General, responsible to stimulate horizontal work on policy coherence across the Organisation and to address potential synergies between different policy areas. In the same year, the OECD also set-up an informal network of focal points for PCD to strengthen the dialogue on this topic between the Organisation and its Members (OECD, 2007a; OECD/DAC, 2007a; interviews, 5,8,14,16,21) and in June 2008 the OECD Ministerial Council explicitly reaffirmed the principle of PCD, stressing the need for greater policy coherence and a better understanding of the 
concept (OECD, 2008). Furthermore, the DAC issued in 2007 and 2008 a number of reports on how to promote PCD at the institutional level, building upon insights it had drawn from its peer reviews (OECD/DAC, 2007b, 2008a, 2008f).

However, it was the DAC's strategic reflection exercise that heralded the breakthrough of PCD within the OECD. This strategic reflection exercise took place between 2007 and 2009 and was a process to review the DAC's mandate, i.e. its role, structure, functioning and composition in the light of the changing development landscape (OECD/DAC, 2008b, 2009a). This effort was undertaken in response to the mounting criticism on the DAC, which revolved around the fact that both developing countries and (re)emerging donors were not represented or unwilling to take part in the Committee's work (Eyben, 2013; Kim \& Lightfoot, 2011). To facilitate the process, the DAC set-up three task-forces, each dealing with a particular topic. Importantly, one of these task forces focused exclusively on the issues of PCD and Global Public Goods (GPGs), following the suggestion of the European Commission, the Netherlands and Finland (OECD/DAC, 2009a, 2010b). Consequently, the DAC's new mandate - which built upon the recommendations of the reflection exercise - puts much emphasis on PCD. More specifically, it puts forward the promotion of policy coherence as one the DAC's key priorities, and stipulates that this needs to be achieved in close collaboration with the rest of the OECD (OECD/DAC, 2011).

The OECD warmly welcomed the DAC's invitation and in May 2011 its Ministerial Council decided that the Organisation needed to engage in drawing its first-ever overarching strategy on development in which particular attention needed to paid to the promotion of PCD (OECD, 2011). This process led to the adoption of the 'OECD Strategy on Development' in May 2012 according to which 'enhancing policy coherence for development is one of the [OECD's] primary objectives' (2012a: 5). In pursue of this objective, the OECD put forward a clear set of priorities, namely (i) develop systematic and evidencebased analyses of the costs and benefits of (in)coherent policies, (ii) establish indicators to monitor progress on PCD, (iii) focus on key issues such as food security, illicit financial flows and green growth and (iv) foster dialogue on PCD within the organisation as well as across different development stakeholders (OECD, 2012a). Ever since, the Organisation has been in the process of implementing these objectives (OECD, 2012b, 2013c). While the DAC continues to identify good practices on how to promote PCD at the institutional level through its peer reviews, the OECD's PCD unit is engaged in a process of drawing a clear-cut definition and measurement of PCD (OECD, 2013c). Moreover, several OECD committees have collectively been undertaking studies to address the potential positive synergies between development cooperation and other policy areas, for example, on food security (OECD, 2013a), 
sustainable development (OECD, 2014b) or illicit financial flows (OECD, 2014a). Finally, in the context of the post-2015 discussions, the OECD Secretariat-General has been undertaken a series of efforts to place PCD high at the international agenda, identifying the principle as one of its main contributions to the international debate (e.g. OECD, 2013a; OECD, 2013b; interviews 3,5,21,23,24). Furthermore, also at the level of the OECD and DAC Member States, efforts are ongoing to further prioritize PCD. To list a few examples, Belgium set-up in 2014 a platform for PCD, Finland has been piloting the OECD's PCD tool on food security (Finland, 2013) and the European Commission's new budget line for scientific research Horizon 2020 - pays, amongst other issues, particular attention to developing a clear methodology for measuring PCD, which then can be uploaded to the level of the OECD. In sum, it can be concluded that while a lot of work is still ongoing, the principle of PCD has received more attention than ever before at all policy levels.

\section{Four causes}

The previous section clearly shows that PCD became a priority for the OECD from 2007 onwards, even if the principle had been around for more than 15 years. This section unravels this puzzle. Taking a complexity-sensitive approach whereby different types of causes are identified at different levels of explanation, we structure our analysis around the four causes identified by Aristotle: material (i.e. the matter out of which things come to be), efficient (i.e. the initiator of change), final (i.e. the ultimate purpose or aim) and formal (i.e. that what shapes or defines matter) causes (Caksu, 2007; Kurki, 2008). (Figure 1). As argued in the introduction, this constitutes an innovative approach to some of the grand debates in IR. We use the Aristotelian categories purely for heuristic purposes, acknowledging that they interact in complex ways.

\section{Material cause}

The material cause is the starting point for analyses according to the Aristotle framework, but it is also probably the most difficult one. Material cause can be defined as 'the matter out of which things come to be'. This 'matter', or 'stuff' (Gorham, 2009: 6), has a 'passive potentiality' (Kurki, 2006: 206) in that it does not directly nor intentionally determine the phenomenon, but it constitutes an essential element without which the phenomenon would not exist. As such material causes are necessary ingredients to any explanation, but they are never sufficient. They tend to be an inherent part of the phenomenon that needs to be explained, which implies that they are not necessarily independent of it and that they do not 
necessarily precede it temporally. Just like formal causes, material causes constitute the social world in the sense of enabling and constraining it (Kurki 2006).

This notion of material cause can be confusing and counter-intuitive in two ways. First, the notion of 'material' should not be understood as interest-related as opposed to ideational. Contrary to, for example, realist or Marxist theories of IR, 'material' here refers not to interests (or 'material capabilities' in Cox' 1981 terminology)but rather to the inherent features of the to-be-explained, which encompasses both ideas and interest related components. The material cause 'out of which' a social event has come to be is inevitably also a social construction. Whereas material causes are easy to identify in exact sciences such as biology (e.g. the genetic code of an organism also 'causes' the organism) or in physics (e.g. the bronze of a statue also 'causes' the statue), it proves harder to pinpoint material causes in a social context. Second, material causes cannot be seen in the traditional definition of 'cause': whereas the formal, final and (most evidently) efficient causes still correspond to mainstream views on causality, the notion of material cause is more difficult to grasp because it is inherently tautological. There is not a clear distinction between the basic characteristic of the social phenomenon to be explained and the causes that have produced it, because the latter are a necessary (but not sufficient) part of the former

Applied to our case, the very notion of 'PCD' forms the material cause for the rise of the idea on the agenda. More specifically, we consider the concept of 'PCD' - the intellectual exercise to define this notion - to be the material cause. Thus, the rise of PCD can be explained through the invention of the concept. This is less trivial than it may seem at first sight: how PCD has been (re)conceptualized also explains why it has eventually been taken up by other 'causes'. Specifically on our case: there was nothing new about the notion of policy coherence, which had long been considered an important prerequisite for effective public management. Also in the context of development policy, it had been long established that the potentially detrimental effects of trade and agricultural policies need to be considered (Forster \& Stokke, 1999a). As mentioned in the previous section, PCD already appeared in the OECD in the early 1990s. However, it was for a long time a 'vaguely defined' and 'flexible' term (Forster \& Stokke, 1999a; OECD/DAC, 1996b, 2001; Stroß, 2014; Thede, 2013). It took until the mid-2000s before experts, officials and policy-makers started to develop more precise and elaborate interpretations (Manning, 2008; OECD, 2006; OECD/DAC, 2007d, 2008f; Thede, 2013). Whereas previously PCD was mostly framed negatively, in terms of avoiding incoherence between development policy and other policy domains, it became increasingly seen as a positive notion, i.e. a tool for transformative 
development. In other words, it evolved from a criticism against existing practices towards a new organizing narrative for development debates.

In short, the success of the PCD concept comes out of its technical and intellectual potential for being a steering concept in international development policy. The elaboration of the notion around the mid2000s proved to be a necessary material condition for its rise on the agenda. However, it cannot be seen as a sufficient condition, which begs the question to underlying explanations. For example, which (f)actors account for policy-makers' increased interest in elaborating the notion of PCD in the mid2000s? Why is it that quite suddenly the notion of PCD was fully embraced and elaborated? Or to put it more simply, why has the 'material' that was fabricated several decades ago quite suddenly become so popular?

As will become clear, this relates to different (f)actors including the activities of norm entrepreneurs, the possibility to use the notion as an excuse for donor laggards, its potential in a context of securitization of foreign aid, and a general commitment to neoliberalism.

\section{Efficient and final cause}

Material causes are necessary but not sufficient as an explanation: there also needs to be an account of why and by whom the 'matter' (i.e. the elaborated PCD notion) was 'triggered' or 'activated' (i.e. prioritized on the agenda). This leads us to consider the efficient and final causes, which both concern the 'agency' side of the Aristotelian framework. Efficient causes closely relate to mainstream explanations of causality in the sense of 'source of change' or 'pushing and pulling' (who or what provoked the change?), whereas final causes address the intentionality behind change (what was the intended impact of the change?).

Searching for the main drivers of the rapid rise of PCD up the political agenda in Paris from 2007, we identify (i) the European Commission (EC), (ii) a small group of EU member states (the Netherlands, Finland and Sweden), (iii) the OECD Secretariat-General, and (iv) the DAC Secretariat. These actors' ambitions to prioritize PCD constitute the efficient cause. They are inspired by final causes such as lifting countries out of poverty, but also bureaucratic politics - i.e. strengthening the position of the OECD Secretariat-General - and institutional survival strategies - i.e. securing the role of the DAC in the changing aid landscape. 
The first and perhaps most important actor that accounts for the rise of PCD in the OECD is the European Commission $^{6}$. Through its efforts in Paris (i.e. putting the item on the agenda) and Brussels (i.e. promoting policy coherence vis-à-vis its Member States), the EC played a catalytic role in making the principle of PCD incontournable. The EC's efforts to promote PCD go back to mid-2000s. While the issue of policy coherence was already introduced with the Treaty of Maastricht (1993), the Commission only became a strong advocate of PCD from 2005 onwards $^{7}$, both in its own policies as well as vis-à-vis its Member States (Carbone, 2008; Hoebink, 2005). This shift was rooted in a growing belief that aid in itself is an insufficient tool to lift countries out of poverty (European Commission, 2005). In parallel to the proceedings in Brussels, the Commission also increasingly emphasized the importance of PCD in the OECD from the mid-2000s onwards, something which has been acknowledged by the DAC (OECD/DAC, 2007c, 2012b). Or as put by a senior-level official from the OECD's PCD unit: "The European Commission has been one of the strongest and most persistent advocates of PCD within the OECD" (interview, 21). This was particularly true from 2007 onwards. The Commission accounts, for example, for the establishment of the task force on PCD and GPGs in 2007, which operated in the context of the DAC's strategic reflection exercise (interviews 1,7,13,16). More specifically, while the DCD was afraid this task force would divert too much attention away from the DAC's key priorities (i.e. the traditional 'ODA' dimension of aid) also other countries (i.e. Canada, Japan, US) had a lukewarm attitude towards the promotion of PCD, typically deriving from their weak performances on the issue ${ }^{8}$ and/or the idea that the new positive interpretation of PCD insufficiently takes into account the fact that politics is about power and conflicting interests (interview 26). However, a majority of DAC members supported the EC's proposal, i.e. mainly EU countries which were either convinced of the idea (e.g. Austria, Belgium, Germany, France, Spain, UK) or unwilling to go against the Commission (e.g. Italy, Greece, Portugal, Poland) (interviews 3,9,11,14-15,18-20). Furthermore, in 2008, the EC was one of the main advocates of PCD at the DAC's High-Level Meeting (OECD/DAC, 2008d) and the OECD's Ministerial Council (interviews $5,9,12)$, illustrating its commitment towards promoting PCD. Also in more recent years, the EC has been one of the strongest advocates of PCD, for example, during the writing of the new DAC mandate and the OECD Strategy on Development (interviews 6,21,22,26-28). Importantly, the EC also played an important role in advancing the understanding of the concept (cf. the material cause) by undertaking various studies on the topic which it presented in meetings of the DAC and the OECD(e.g. OECD, 2007a; OECD/DAC, 2008e, 2012a). Moreover, the Commission helped the OECD with the establishment of the informal network on PCD focal point in 2007, building upon its experiences in setting-up such a network in 2003 (OECD, 2007a), and it maintained close relations with the PCD unit with whom it regularly 
exchanged views (interviews 21,24) and organized events (e.g. European Commission, 2013; OECD/DAC, 2009b). Finally, in terms of financial support, the EC has been one of the larger voluntary contributors to the OECD's and DAC's work on PCD (OECD/DAC, 2008c; interviews, 21-24,26-27).

A second group of actors that account for the rise of PCD are the Netherlands, Finland and to a lesser extent $^{9}$ also Sweden. Similar to the EC, these countries have systematically put the issue on the agenda of the DAC and OECD, motivated by a shared conviction that ODA in itself is a necessary but insufficient tool to foster development (interviews 2,21,26). Furthermore, what these countries have in common is that they perform well above average on PCD in comparison to the other DAC and OECD members (see e.g. Concord, 2013; OECD, 2009), making it easy to endorse and actively promote the principle (interviews 2 \& 26). During the DAC's strategic reflection exercise, for example, they advocated in favor of prioritizing PCD- the task force on PCD and GPGs was also chaired by a Dutch official (OECD/DAC, 2010a), a plea which was repeated at the OECD Ministerial Council of 2008 (interviews 5,9,12). Furthermore, the Netherlands, Finland and Sweden have devoted an important part of their voluntary contributions to the DAC's budget to advancing its work on PCD from 2006 onwards (OECD/DAC, 2006; 2008c; interviews $2,9,14,26$ ). They have also been engaged in organizing events ${ }^{10}$ on the topic and/or conducted pilot-studies on PCD in collaboration with the OECD's PCD unit (Department of Foreign Affairs Finland, 2013; OECD, 2007b).

Third, the OECD Secretariat-General has been an important driver of the PCD agenda. More specifically, it took a particular interest in the promotion of the principle from 2007 onwards, whereas before the DAC had typically been the main - and often only - advocate of PCD. This shift can first of all be explained by the election of Angel Gurría as Secretary-General of the OECD in 2006. Unlike his predecessors, he took a personal interest in the promotion of PCD, convinced of the intrinsic value of the concept, and therefore was in 2007 one of the main architects of the PCD unit which operates from within his own office (Manning, 2008; interviews 14,22,23). However, the OECD's interest towards promoting PCD should also be seen in the light of the Organisation's efforts to become a more modern and legitimate organisation. While in the 1990s and early 2000s the OECD successfully expanded its membership and modernized its decision-making procedures, from the mid-2000s onwards its focus shifted to finding new flagships which could give direction to the work of Organisation (Carroll \& Kellow, 2011). PCD was considered to be such an issue given its potential to cover and link different areas of OECD expertise (cf. material cause). Moreover, the promotion of PCD was also seen as a way to strengthen the position of the Secretariat-General as a central actor in the OECD's decision-making 
process and it allowed the OECD to engage in the debates on achieving the MDGs as well as the post2015 development agenda (Atwood, 2012; interviews 14,16-17,21,28).

Finally, also the DAC played an important role in the rise of PCD. As reflects from our empirical analysis, it has always been the main driver of the PCD agenda within the OECD. However, in the period before 2007 it mainly framed PCD in a negative way, i.e. avoiding incoherence, while ignoring the notion of PCD being a transformative notion (see supra). This can be explained by the fact that the DAC did not want to divert too much attention away from its key priorities, i.e. its work on ODA and aid effectiveness. However, the DAC changed its stance on the issue from 2007 onwards. At that time the DAC faced an existential crisis due to the changing international aid landscape, the emerging 'beyond-aid' discourse and the mounting criticism on the legitimacy of its work, explaining why the Committee undertook its strategic reflection exercise (OECD/DAC, 2008b; 2009a; interviews 1,14). In this context, the promotion of PCD - more specifically its transformative notion - was seen as a strategy for institutional survival (Carbone, 2011; interviews, 1,11,14,20,26). This most clearly reflects from various speeches of the then DAC Chair Eckhard Deutscher according to whom "the development community will become increasingly marginalised [...] without a strong and serious engagement with PCD" (2009), which "is also why the DAC has decided to put a much stronger emphasis on PCD in the future" (2010). Moreover, it allowed the DAC to strengthen its ties with the OECD. While traditionally the DAC had always been a quasi-independent body operating within the OECD's institutional framework - and was keen on maintaining this autonomy (Masujima, 2004; Verschaeve \& Takacs, 2013), it felt that it could better face the challenges ahead by joining efforts with the OECD(interviews 1,3,9,14,21).

\section{Formal cause}

Although we have identified the various actors that played a significant role in the prioritisation of PCD (efficient cause), and showed why they decided to embrace this policy standard more actively from 2007 onwards (final cause), the analysis of active causes is silent on the underlying, structural factors that enabled the rise of PCD. In general scholars tend to concentrate on the role of the aforementioned 'active' pushing and pulling causes, neglecting the institutional and ideational forces that constrain and enable them (Kurki, 2006: 207). Hence, in order to understand the prioritisation of PCD since 2007 one has to look more carefully at the constitutive 'formal causes' that have enabled such a rise. While Aristotle referred to 'formal causes' as 'that which shapes or defines matter' (Kurki, 2006: 207), in social sciences these can be understood best as the 'ideas, rules, norms and discourses' that define and structure social practice. In contrast to the 'active' efficient and final causes that we discussed above, 
formal causes should be seen as intrinsic, constitutive and structure-related causes. Consequently, we argue that both the institutional and ideational structure in which the aforementioned actors operate are key to fully understand the rise of PCD on Western donors' development agendas.

First, in relation to the institutional structure, we can point to the EU's dominance in Paris. Indeed, in order to understand why the EU has been able to place PCD on top of the agenda, we cannot ignore its significant weight within both the OECD and DAC. While in the case of the OECD, EU member states constitute for 21 of the 34 members, they account for 20 of the 29 members in the DAC. Moreover, the EU - referring to the institution - is represented in the work of both the OECD and DAC, respectively, as a full participant and member (Verschaeve \& Orbie, 2015). Importantly, this allows the EU - and the EC in particular - to heavily influence the decision-making of the OECD and DAC, even though decisions in both institutions are taken by consensus and the EU typically does not present itself as a single-voiced bloc (Verschaeve \& Takacs, 2013). Indeed, if certain priorities, norms or values have been established in Brussels, as was the case with PCD, it is very hard for non-EU members to shift the tone/direction of the debate.

Another institutional factor that has enabled the rise of PCD on the OECD agenda relates to the mere existence of the EU as a structure within which reluctant member states have come to accept policy standards such as PCD. Through their membership of the EU, even laggards such as Greece, France and Italy have committed to PCD as a principle. The EC and several member states (in particular the Nordicplus) have systematically promoted PCD since the early 2000s. In doing so, they have also engaged some of the less engaged member states in (at least rhetorical) support of PCD (Carbone 2008; Hoebink 2005). It could be argued that because of these commitments within the EU framework, these countries found it difficult not to embrace PCD at the level of the OECD and DAC given that it had acquired within the EU a more or less 'unobjectionable ${ }^{11}$, status (interviews 9,18-19). Stated otherwise, in the absence of the EU structure, some members may have sided with countries such as the US, Canada and Japan; however their endorsement of the PCD principle within the Brussels context made it nearly impossible to resist the norm in Paris (OECD/DAC, 2008d; interviews 3,9,11,14-15,18-20). As such internal EU commitments constitute a magnifying impact on the international level.

More broadly, globalization has entailed an increasingly blurred distinction between different policy levels (e.g. national, European, global) as well as different policy areas (e.g. development, trade, environment), thereby providing an enabling environment for the PCD concept. In this context, it is widely accepted that ODA alone is an insufficient tool to eradicate poverty and achieve sustainable and 
inclusive development. This stems from the magnitude and complexity of the challenges which the international community is facing today. Indeed prospects of countries are shaped by a wide range of interrelated challenges, ranging from the eradication of poverty, climate change or food crises to migration, insecurity, unemployment or growing inequality (e.g. EU, 2013; OECD, 2013b; UN 2014) and an ever-increasing number of actors which generate both opportunities and challenges for achieving development. All this illustrates the changing nature of the international system and the increased blurriness between different policy levels, areas and actors. Obviously, in such context, there is an increased need for policy coherence, both at an institutional and intellectual level.

Second, the ideational structure in the second half of the 2000s had a conditioning impact on the acceptance of PCD as a new priority of Western donors, in the sense of providing an enabling intersubjective structure within which PCD became a feasible and legitimate project. This period shows the emergence of a strong anti-aid discourse. It is striking that the rise of PCD coincides with the reemergence of a fierce debate on the nature of international development cooperation, spurred by the publication of a number of influential works such as Jeffrey Sachs' 'The end of poverty' (2006), William Easterly's 'The White Man's Burden' (2006) or Dambisa Moyo's 'Dead Aid' (2009) ${ }^{12}$. The ideational context is one in which Western donors' aid practices are severely questioned. At a more fundamental level, the prioritisation of PCD can thus be seen as an answer from Western donors who come to realize that their foreign aid model is increasingly under pressure (Deutscher, 2010; OECD, 2009; interviews $5,9,13)$. Arguably, this growing awareness that enabled the embracement of the PCD norm, was further strengthened by the changing landscape, characterized amongst others by the rise of the BRICS. At the same time, the rise of Western donors' aid budgets had come to an end between 2005-2007. In line with pledges made at the 2002 UN Monterrey Conference which focused on Financing for Development, average ODA budgets had gradually increased since the early 2000s, but even before the global economic crisis started to hit most Western economies it had become clear that most donors were cutting their aid budgets. The PCD agenda provides the perfect legitimation for this, since PCD is essentially about development in the absence of growing ODA budgets (Deutscher, 2009; Delputte, Lannoo, Orbie \& Verschaeve, 2015; interviews 12,21,25,27).

Finally, the PCD agenda also fits within a broader trend of securitisation (Thede, 2013), whereby development is increasingly considered as part and parcel of a broader foreign policy agenda. While the international development consensus until the early 2000s focused on the objective of poverty reduction, since $9 / 11$ we have witnessed a growing consensus that more attention should be paid to the 
security-development nexus. The mutual linkages between development and security are obvious and the need for coherence between development and foreign policy can hardly be denied. However, there has been an acute fear by critics that the former would become subordinated to the latter, whereby national security considerations would take priority over development concerns. There is also an institutional dimension to the discourse on the security-development nexus, since in many countries the ministry of foreign affairs' clout over development policy has been growing - examples are Australia, Canada, Germany, Ireland, the Netherlands, New Zealand, Norway (Thede, 2013). Also at the EU level, the creation of the European External Action Service and its partial incorporation of former DG Development staff and expertise can be seen in the light of the securitisation of EU foreign policy (Furness, 2010). Both the EU and the DAC have also become less technocratic and development-oriented and more politically oriented institutions. A specific illustration of this within the DAC is that there has been a shift in the profile of member state delegates since the mid-2000s, from senior officials of the development administrations to less senior diplomats from the ministries of foreign affairs (interviews $1,3,8,15)$. Thus, the broader context is one in which the development sub-systems of several countries has been weakening. As such the PCD agenda can be seen as both an attempt to reconquer the loss of power of the development administrations and an indication of the growing impact of non-development spheres.

\section{Conclusion}

This paper focused on the rise of PCD on the Western donors' aid agenda. While the concept already appeared in the work of OECD in the early 1990s, it took until 2007 before it became one of the Organisation's key priorities. Furthermore PCD evolved during this period from being a negative concept, i.e. avoiding policy incoherence, to a positive concept, i.e. the notion of PCD being a tool for transformative development. Taking a complexity-sensitive approach whereby we used the Aristotelian framework of material, efficient, final and formal causes, this paper shows that the rise of policy coherence is not as contingent as it looks like.

Indeed, this study shows that while existing research provides us some answers why PCD thrives well, it fails to grasp the full complexity of the issue as it only takes stock of the active causes and ignores the constitutive causes (cfr. figure 1). More specifically, and in parallel with what has been suggested in literature by some observers, our findings confirm that the elaborated notion of PCD (i.e. the 'matter') was activated by a number of actors, i.e. (i) the EC, (ii) the Netherlands, Finland and Sweden, (iii) the OECD Secretariat-General and (iv) the DCF. They successfully put PCD on the international agenda, 
inspired by a shared belief in its transformative power. Moreover, actors such as the OECD SecretariatGeneral and the DAC displayed bureaucratic interest in advancing the PCD agenda.

The added-value of this paper, however, lays in the fact that it moves beyond such 'efficient' and 'final causes' by also addressing the constitutive causes underlying the rise of PCD. More specifically, our analysis shows first of all that the success of the PCD concept comes out of its intellectual potential for being a steering concept in international development cooperation. While it had been established long before 2007 that donors need to consider the potentially detrimental effects of other policy areas, the technical elaboration of PCD as a concept around the mid-2000s proved to be a necessary precondition for its rise on the agenda.

Second, our findings illustrate that the structure in which the aforementioned actors operate enabled the rise of PCD (i.e. formal causes).The institutional structure in which the aforementioned actors operate is characterized by an overrepresentation of the EU, a magnifying impact of internal EU commitments on laggards within the EU, and blurred boundaries because of globalization processes. The ideational structure in the second half of the 2000s also had a conditioning impact, in the sense that the growing anti-aid thinking, the changing aid landscape, and stalling ODA budgets provided an enabling climate within which policy coherence became a feasible and legitimate project. The rise of PCD also fits within a broader trend of securitisation, whereby development is increasingly considered as part and parcel of a broader foreign policy agenda.

In sum, this study shows that the rise of PCD is not as contingent as it looks. The implications of this finding are twofold. First, our study shows that PCD is there to stay in the work of the OECD. Even if the aforementioned actors would become less engaged with the PCD agenda, which at present is not the case, the underlying constitutive causes will continue to create a structure in which the concept thrives well. Second, this study raises the broader question to what extent the concept can really become a central element of the post-2015 agenda. While the aforementioned actors are keen on placing PCD at the heart of the discussions, one cannot ignore the fact that a number of constitutive causes will provide less of an enabling factor in the development community at large. While in the context of the OECD, the EU proves to be an important formal cause - both in terms of structure and overrepresentation - this obviously is not the case (or to a lesser extent) in the context of the ongoing UN negotiations. Moreover, other stakeholders such as developing countries or emerging donors may be more reluctant towards PCD given that they operate in a different ideational structure. 


\section{Notes}

1) Also the study of the OECD and the DAC have thus far paid no attention to the rise of PCD (Carroll \& Kellow, 2011; Eyben, 2013; Ruckert, 2008).

2) As various officials were only willing to share their views on the condition of absolute anonymity, interviews are indicated by a general reference only. A list of interviews can be found in the reference section.

3) One of the authors took part as an observer in the work of a number of DAC meetings in the period 2012-2013.

4) In the remainder of this article, we distinguish between the OECD and the DAC. As outlined by several authors (e.g. Ruckert, 2008; Masujima, 2004; Verschaeve \& Orbie, 2015), this distinction is important, stemming from the fact that the DAC holds a largely autonomous position within the OECD. For example, the Committee has its own membership criteria and it is the only one allowed to voice its own opinions without gaining prior approval from the OECD (Verschaeve \& Orbie; 2015). However, one can not completely disregard the OECD, especially not on cross-cutting issues such as PCD on which the OECD is also able to take initiatives, ideally - but not necessarily - in collaboration with the DAC, explaining why we focus on both actors.

5) Their main motivation was that the existing - and often strong - incoherencies within most aid agencies were detrimental for more aid effectiveness.

6) We explicitly distinguish between the EU (i.e. the European Commission) and the different EU members of the DAC for two reasons. First, the EU has always been a full member of the DAC, alongside its Member States (Verschaeve \& Orbie, 2015). Second, the EU does not coordinate with its Members in Paris. Rather, the modus vivendi is that the EU delegation and the different Member States operate as autonomous actors, though, if on certain issues collect targets or commitments have been made previously in Brussels, they de facto act as a more homogenous group (Verschaeve \& Tackas, 2013).

7) Before, especially in the 1990s, the EU almost completely overlooked the issue, sparking much criticism among NGOs and Member States(Carbone, 2008).

8) This also reflects from the Commitment to Development Index of the Centre for Global Development, which lists Canada, Japan or the US in the bottom half of the index.

9) In the sense that the Netherlands and Finland have been more vocally on the issue.

10) In May 2007, for example, the Netherlands hosted in Noordwijk a High-Level Meeting to promote more research for diseases of importance to developing countries. 
11) Referring to the concept of 'unobjectionable norms' as put forward by Ole Elgström (2004), which are norms that are impossible to openly oppose.

12) Illustrative for this point is the fact that Dambisa Moyo presented her book during the meeting of the OECD's informal network of PCD focal points on 8 June 2009 (OECD, 2009).

\section{Figures}

Figure 1

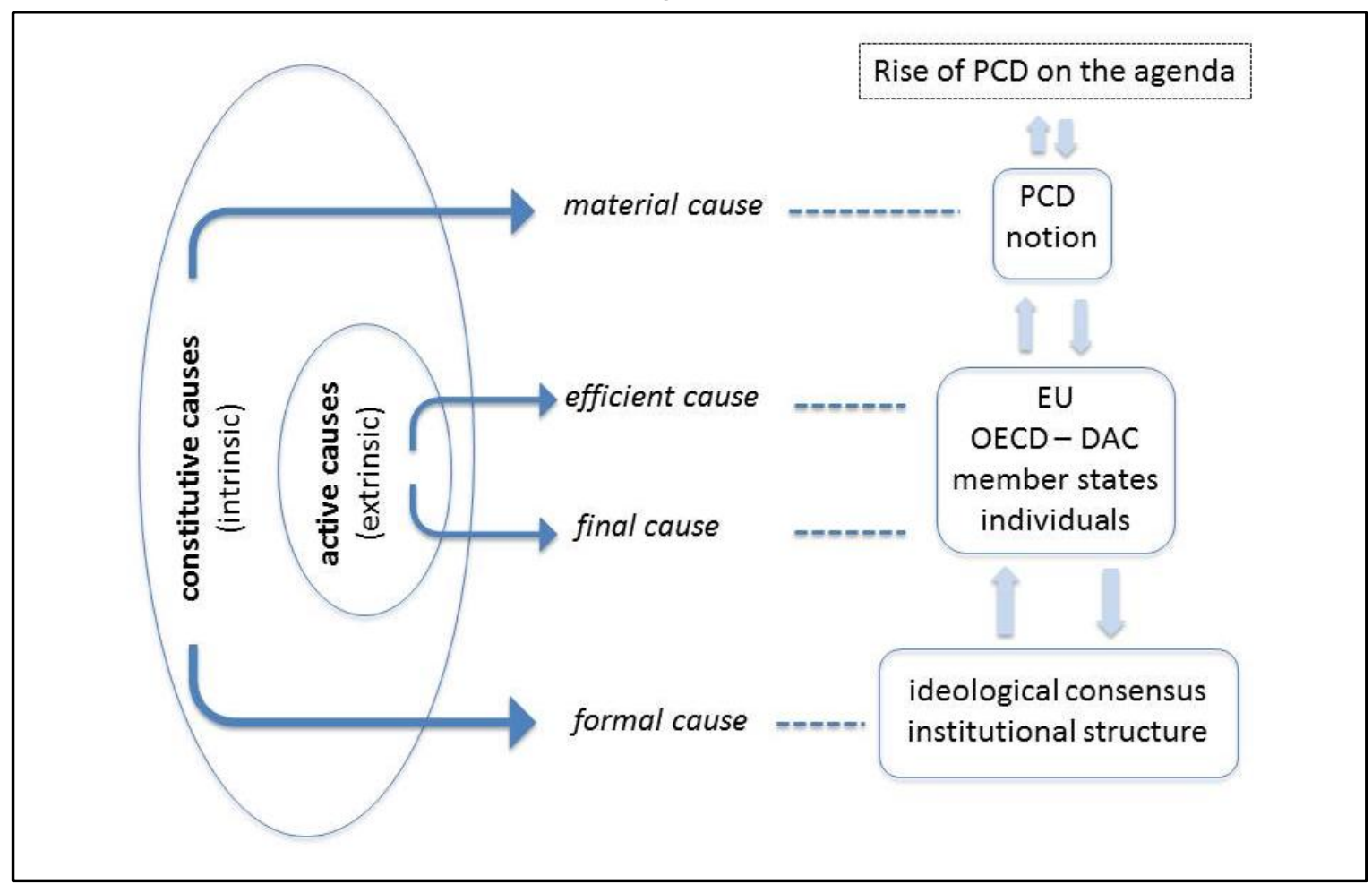

Aristotelian Framework of Causality (partly based on Kurki 2008; Bailey 2008)

\section{References}

Ashoff, G.(1999). The coherence of policies towards developing countreis: the case of Germany. In J. Forster \& O. Stokke (Eds.), Policy Coherence in Development Co-operation. Abingdon: Frank Cass Publishers.

Ashoff, G.(2005). Enhancing policy coherence for development: justification, recognition and approaches to achievements. DIE Studies (11).

Atwood, B.(2012). ODA and beyond: setting the framework, Speech by the DAC Chair at Society for International Development, Amsterdam, 25 /12/2012.

Bailey, D. J.(2008). Explaining the underdevelopment of 'Social Europe': a critical realization. Journal of European Social Policy,18(3),232-245.

Bennett, A., \& George, A. (2005). Case Studies And Theory Development In The Social Sciences: Mit Press. Caksu, A.(2007). Ibn Khaldun and Hegel on Causality in History: Aristotelian Legacy Reconciderd Asian Journal of Social Science,35,46-83. 
Carbone, M.(2008). Mission Impossible: the European Union and Policy Coherence for Develoment. Journal of European Integration,30(3),323-342.

Carbone, M.(2011). Beyond Aid: Policy Coherence adn Europe's Development Policy. In G. Carbonnier (Ed.), International Development Policy: Aid, Emerging Economies and Global Policies. Basingstoke: Palgrave MacMillan.

Carbone, M. (Ed.).(2009). Policy Coherence and EU Development Policy. London: Routledge.

Carroll, P., \& Kellow, A.(2011). The OECD. A study of organisational adaptation. Cheltenham: Edward Elgar Publishing.

Carroll, P., \& Kellow, A.(2012). The OECD. In K. E. Jorgensen \& K. V. Laatikainen (Eds.), Routledge handbook on the European Union and international institutions. London: Routledge.

Chandler, D(2007). The Security-Development Nexus and the Rise of "Anti-Foreign Policy". Journal of international Relations and Development,10(4).

Cox, R.(1981). 'Social Forces, States and World Orders: Beyond International Relations Theory, Millennium: Journal of International Studies 10(2): 126-155.

Department of Foreign Affairs Finland.(2013). Report: Food security in developing countries can be enhanced through an interplay of policies.

Delputte, S., Lannoo, S., Orbie, J. \& Verschaeve, J.(2015). Europeanization of aid budgets: nothing is as it seems, Perspectives on European Politics and Society. Deutscher, E. (2009). Speech by the DAC chair at High-Level Parliamentary conference on PCD and Migration, Brussels, 12/02/2009.

Deutscher, E.(2010). Speech by the DAC chair at 2010 DCF meeting, New York,29/06/2010.

DIIS.(2013). European Union Development Cooperation in a changing global context. Danish Institute for International Studies, Report(2).

Easterly, W.(2006). The White Man's Burden: Why the West's Efforts to Aid the Rest Have Done So Much III and So Little Good. Penguin Group US.

ECDPM.(2014). Bringing Policy Coherence for Development into the Post-2015 Agenda - Challenges and Prospects. Discussion Paper, 163.

ECDPM.(2012). Measuring Policy Coherence for Development - final report. May 2012.

Elgström, O.(2004). 'Consolidating unobjectionable norms', in O. Elgström \& C. Jönsson (Eds.) European Union Negotiations: processes, networks and institutions. London: Routledge.

Eun, Y.(2012). Why and how should we go for a multicausal analysis in the study of foreign policy?(Meta) theoretical rationales and methodological rules. Review of International Studies38(04),763-783.

European Commission.(2005). Policy coherence for development - accelerating progress towards attaining the Millennium Development Goals.COM(2005)134.

European Commission.(2013). Agenda European Development Days.

EU.(2013). Council conclusions of 25 June 2013 on The Overarching Post 2015 Agenda. Brussels.

Eyben, R.(2013). Struggles in Paris: The DAC and the Purposes of Development Aid. European Journal of Development Research,25(1),78-91.

Forster, J., \& Stokke, O.(1999a). Coherence of policies towards developing countries: approaching the problematique. In J. Forster \& O. Stokke (Eds.), Policy Coherence in Development Co-operation. Abingdon: Frank Cass Publishers.

Forster, J., \& Stokke, O.(1999b). Policy coherence in development co-operation. Abingdon: Frank Cass.

Führer, H.(1996). The story of Official Development Assistance: a history of the development assistance committee and the development co-operation directorate in dates, names and figures. Paris: OECD Publishing.

Furness, M.(2010). The European External Action Service: A New Institutional Framework for EU Development Cooperation. DIE Discussion Paper (15/2010).

Gorham, G.(2009). Philosophy of science : a beginner's guide. Oxford: Oneworld.

Hall, P.(1997). The role of interests, institutions and ideas in the comparative political economy 
of the industrialized nations. In M. Lichbag, \& A. Zuckerman (Eds.), Comparative Politics. Cambridge: Cambridge University Press

Hoebink, P.(1999). Coherence and Development Policy: the case of the EU. In J. Forster \& O. Stokke (Eds.), Policy Coherence in Development Co-operation. Abingdon: Frank Cass Publishers.

Hoebink, P.(2005). The Treaty of Maastricht and Europe's development co-operation. Amsterdam: Aksant Academic Publishers.

Hoebink, P.(2010). Some recent developments in European International and Development Cooperation. In P. Hoebink (Ed.), European Development Cooperation: in between the Local and the Global. Amsterdam: Amsterdam University Press.

Janus, H., Klingebiel, S., \& Paulo, S.(2014). Beyond Aid: A Conceptual Perspective on the Transformation of Development Cooperation. Journal of International Development (online).

Jutila, M.(2009). Taming Eastern Nationalism: Tracing the Ideational Background of Double Standards of Post-Cold War Minority Protection. European Journal of International Relations, 15(4),627-651.

Kim, S., \& Lightfoot, S.(2011). Does 'DAC-Ability' Really Matter? The emergence of non-DAC Donors: Introduction to Policy Arena. Journal of International Development,23(5),711-721.

Kurki, M.(2006). Causes of A Divided Discipline: Rethinking the Concept of Cause in International Relations Theory. Review of International Studies,32(2),189-216.

Kurki, M.(2008). Causation in International Relations: Reclaiming Causal Analysis: Cambridge University Press.

Makhan, D.(2012). The EU's coordination dilemma: Linking Trade and Development in the ACP-EU Economic Partnership Agreements and 'Aid for Trade'. In S. Gänzle, S. Grimm \& D. Makhan (Eds.), The Europan Union and Global Development. An 'enlightened superpower' in the making? Basingstoke: Palgrave MacMillan.

Manning, R.(2008). The DAC as a Central Actor in Development Policy Issues: Exeperiences over the Past Four Years. DIE Discussion Paper (vol. 7).

Masujima, K.(2004). Good governance and the Development Assistance Committee: ideas and organizational constraint. In M. Boas \& D. McNeill (Eds.), Global institutions and devleopment: framing the world? London: Routledge.

McKelvey, B.(2004). Towards a complixity science of entrepreneurship. Journal of Business Venturing,19,313-341.

Morrissey, O.(1999). Aid and Trade Policy (In)Coherence. In J. Forster \& O. Stokke (Eds.),Policy Coherence in Development Co-operation. Abingdon: Frank Cass.

Moyo, D.(2009). Dead Aid: Why Aid Is Not Working and How There Is a Better Way for Africa. Farrar, Straus and Giroux.

ODI, DIE, \& ECDPM.(2013). European Report on Development.

OECD.(2002). OECD Action for a Shared Development Agenda.

OECD.(2006). Trade, Agriculture and Development. Policies working together. Paris: OECD Publishing.

OECD.(2007a). First meeting of the informal network of PCD Focal Points, 30/11/2007.

OECD.(2007b). High-Level Forum on Policy Coherence: Availability of Medicines for Neglected and

Emerging Infectious Diseases (HLF), June 2007, Noordwijk-aan-Zee, Netherlands.

OECD.(2008). Ministerial Declaration on PCD.

OECD.(2009). SG/PCD/M(2009)1 - Looking for results-coherent policies for development

OECD.(2011). Framework for an OECD Strategy on Development: Meeting of the OECD Council at

Ministerial Level- Paris, 25-26/05/2011

OECD.(2012a). OECD Strategy on Development.

OECD.(2012b). Policy framework for PCD.

OECD.(2013a). Better policies for Development: In focus 2013: Policy Coherence for Development and Global Food Security. Paris: OECD Publishing. 
OECD.(2013b). Beyond the Millennium Development Goals:Towards an OECD contribution to the post2015 agenda.

OECD.(2013c). C/MIN(2013): Meeting of the Council at Ministerial Level,29-30/05/2013, Overview Paper on the Implementation of the OECD Strategy on Development.

OECD.(2014a). Better Policies for Development: Policy Coherence and Illicit Financial Flows. Paris: OECD Publishing.

OECD.(2014b). Coherence for development, Issue 3, Responsible Business Conduct: From good intentions to sustainable development.

OECD/DAC.(1991). DCD/DAC(91)17: Development Co-operation and the Challenge of Policy Coherence in the New International Context.

OECD/DAC.(1991b). DCD/DAC(91)21/REV1: Issues for the 1991 High-Level Meeting

OECD/DAC.(1991C). DCD/DAC/M(91)10/PROV: Summary record of the Thirtieth High-Level Meeting.

OECD/DAC.(1992). Chairman Report 1992.

OECD/DAC.(1994a). DCD/DAC/M(94)9/PROV.

OECD/DAC.(1994b). OCDE/GD(94)106.

OECD/DAC.(1995). DCD/DAC/M(95)4/PROV.

OECD/DAC.(1996a). DCD/DAC/M(96)5/PROV.

OECD/DAC.(1996b). Shaping the 21st century: the contribution of development co-operation.

OECD/DAC.(2000a). DCD/DAC/M(2000)7/PROV.

OECD/DAC.(2000b). DCD/DAC/M(2000)8/PROV.

OECD/DAC.(2001). The DAC Guidelines - Poverty Reduction. Paris: OECD Publishing.

OECD/DAC.(2002). DCD/DAC(2002)31.

OECD/DAC.(2005). Paris Declaration on Aid Effectivneess..

OECD/DAC.(2006). DCD/DAC(2006)30/REV1-Draft programme of work and budget for 2007-2008. Paris.

OECD/DAC.(2007a). DCD/DAC/M(2007)6/FINAL.

OECD/DAC.(2007b). Development Co-operation Report 2007.

OECD/DAC.(2007c). European Community Peer Review.

OECD/DAC.(2007d). Policy Coherence for Development: Synthesis Report on the OECD-DAC Peer Review.

OECD/DAC.(2008a). COM/SG/DCD(2008)1/REV1: Synthesis report on PCD.

OECD/DAC.(2008b). DCD(2008)27/REV1: Strategic Reflection Excercise: Views from former DAC Chairs.

OECD/DAC.(2008c). DCD/DAC(2008)31/REV2-Draft Programme of Work and Budget.

OECD/DAC.(2008d). DCD/DAC/M(2008)5/FINAL.

OECD/DAC.(2008e). DCD/DAC/RD(2008)1/RD1.

OECD/DAC.(2008f). PCD Lessons Learned. Policy Brief, December 2008.

OECD/DAC.(2009a). DCD/DAC(2009)23/Final: DAC Reflection Excercise.

OECD/DAC.(2009b). DCD/DAC/RD(2009)3/RD1.

OECD/DAC.(2010a). DCD/DAC(2010)13/REV1.

OECD/DAC.(2010b). DCD/DAC/RD(2010)2/RD3.

OECD/DAC.(2011). DCD/DAC(2010)34/Final: DAC Mandate 2011-2015.

OECD/DAC.(2012a). DCD/DAC/AR(2012)1/25.

OECD/DAC.(2012b). European Union Peer Review.

Pérez Álvarez, M.(2009). The four causes of behavior: Aristotle and Skinner. International Journal of

Psychology and Psychological Therapy, 9(1) 45-57.

Picciotto, R. (2005). The evaluation of policy coherence for development. Evaluation, 11(3),311-330.

Ruckert, A.(2008). Making Neo-Gramscian sense of the Development Assistance Commitee. In R. Mahon

\& S. McBride (Eds.), The OECD and Transnational Governance. Vancouver: UBC Press.

Sachs, J.(2006). The End of Poverty: Economic Possibilities for Our Time. Penguin Books. 
Stroß, S.(2014). One goal, many paths. The promotion of Policy Coherence for Development in EU policy formulation. Ph.D., University of Köln, Köln.

Sunday, J., Eyles, J., \& Upshur, R.(2001). Applying Aristotle's doctrine of causation to aboriginal and biomedical understandings of diabetes. Culture, medicine adn psychiatry,25,63-85.

Thede, N. (2013). Policy Coherence for Development and Securisation: competing paradigms or stablising North-South hierarchies? Third World Quarterly,34(5),784-799.

UN.(2013). A New Global Parntership: eradicate poverty and transform economies through sustainable developement. The Report of the High-Level Panel of Eminent Persons on the Post-2015 Development Agenda

UN.(2014). The road to dignity by 2030. Ending poverty, Transforming All Lives and Protecting the Planet. Synthesis report of the Secretary-General on the Post-2015 Agenda. New York.

Verschaeve, J., \& Orbie, J.(2015). Once a member, always a member? Assessing the importance of time in the relationship between the European Union and the Development Assistance Committee. Cambridge Review of International Affairs.

Verschaeve, J., \& Takacs, T.(2013). The EU's international identity: the curious case of the OECD. In H. Dewaele \& J.-J. Kuipers (Eds.), The emergence of the European Union's international identity. Views from the global arena. Leiden: Martinus Nijhoff Publishers.

Wendt, A.(2003). Why a World State is Inevitable. European Journal of International Relations,9(4)491542.

Williams, M.(2005). The Third World and Global Environmental Negotiations: Interests, Institutions and Ideas. Global Environmental Politics , 5(3), 48-69

Youngs, R.(2007). Fusing security and development: just another Euro-platitude. Journal of European Integration,30(3),419-437.

\section{Interviews}

MS= Member State

1: MS official, 16/01/2012, Paris

2: MS official, 16/01/2012, Paris

3: DAC official, 17/01/2012, Paris

4: DAC official, 19/01/2012, Paris

5: (ex)OECD official, 19/02/2012, Skype

6: MS official, 20/02/2013, Skype

7: MS official, 28/03/2012, Brussels

8: MS official, 11/06/2012, Paris

9: MS official, 11/06/2012, Paris

10: DAC official, 11/06/2012, Paris

11: MS official, 11/06/2012, Paris 
12: MS official, $13 / 06 / 2012$, Paris

13: MS official, 04/12/2012, London

14: (ex)DAC official, 05/12/2012, London

15: (ex)MS official, , 06/12/2012, London

16: (ex)MS official, OECD official, 06/12/2012, London

17: MS official, 17/10/2013, Paris

18: MS official, 22/10/2013, Paris

19: MS official, 22/10/2013, Paris

20: MS official, 28/10/2013, Paris

21: OECD official, $28 / 10 / 2013$, Paris

22: OECD official, 28/10/2013, Paris

23: OECD official, 28/10/2013, Paris

24: OECD official, 28/10/2013, Paris

25: OECD official, $30 / 10 / 2013$, Paris

26: DAC official, 05/11/2013, Paris

27: MS official, $13 / 11 / 2013$, Paris

28: MS official, 13/11/2013, Paris 